\title{
Synthesis of thermoelectric magnesium-silicide pastes for 3D printing, electrospinning and low-pressure spray
}

\author{
A. C. Marques ${ }^{1}$ - Davide Miglietta ${ }^{1,2}$. G. Gaspar ${ }^{3} \cdot$ A. C. Baptista ${ }^{1} \cdot$ A. Gaspar ${ }^{1} \cdot$ P. Perdigão ${ }^{1} \cdot$ I. Soares $^{1} \cdot$ C. Bianchi ${ }^{1}$. \\ D. Sousa ${ }^{1}$ - B. M. Morais Faustino ${ }^{1}$ - V. S. Amaral ${ }^{4} \cdot$ T. Santos $^{4}$ - A. P. Gonçalves ${ }^{5} \cdot$ R. C. da Silva ${ }^{6} \cdot$ Fabrizio Giorgis $^{3}$. \\ I. Ferreira ${ }^{1}$
}

Received: 20 December 2018 / Accepted: 30 September 2019 / Published online: 9 October 2019

(c) The Author(s) 2019

\begin{abstract}
In this work, eco-friendly magnesium-silicide $\left(\mathrm{Mg}_{2} \mathrm{Si}\right)$ semiconducting ( $n$-type) thermoelectric pastes for building components concerning energy-harvesting devices through 3D printing, spray and electrospinning were synthetized and tested for the first time. The $\mathrm{Mg}_{2} \mathrm{Si}$ fine powders were obtained through the combination of ball milling and thermal annealing under $\mathrm{Ar}$ atmosphere. While the latter process was crucial for obtaining the desired $\mathrm{Mg}_{2} \mathrm{Si}$ phase, the ball milling was indispensable for homogenizing and reducing the grain size of the powders. The synthetized $\mathrm{Mg}_{2} \mathrm{Si}$ powders exhibited a large Seebeck coefficient of $\sim 487 \mu \mathrm{V} / \mathrm{K}$ and were blended with a polymeric solution in different mass ratios to adjust the paste viscosity to the different requirements of 3D printing, electrospinning and low-pressure spray. The materials produced in every single stage of the paste synthesis were characterized by a variety of techniques that unequivocally prove their viability for producing thermoelectric parts and components. These can certainly trigger further research and development in green thermoelectric generators (TEGs) capable of adopting any form or shape with enhanced thermoelectric properties. These green TEGs are meant to compete with common toxic materials such as $\mathrm{Bi}_{2} \mathrm{Te}_{3}, \mathrm{PbTe}$ and $\mathrm{CoSb}$ that have Seebeck coefficients in the range of $\sim 290-700 \mu \mathrm{V} / \mathrm{K}$, similar to that of the produced $\mathrm{Mg}_{2} \mathrm{Si}$ powders and lower than that of 3D printed bulk $\mathrm{Mg}_{2} \mathrm{Si}$ pieces, measured to be $\sim 4866 \mu \mathrm{V} / \mathrm{K}$. Also, their measured thermal conductivities proved to be significantly lower $(\sim 0.2 \mathrm{~W} / \mathrm{mK})$ than that reported for $\mathrm{Mg}_{2} \mathrm{Si}(\geq 4 \mathrm{~W} / \mathrm{mK})$. However, it is herein demonstrated that such thermoelectric properties are not stable over time. Pressureless sintering proved to be indispensable, but difficultly achievable by long thermal annealing (even above $32 \mathrm{~h}$ ) in inert atmosphere at $400{ }^{\circ} \mathrm{C}$, at least for bulk $\mathrm{Mg}_{2} \mathrm{Si}$ pieces constituted by a mean grain size of $2-3 \mu \mathrm{m}$. Hence, for overcoming this sintering challenge and become the silicide's extrusion viable in the production of bulk thermoelectric parts, alternative pressureless sintering methods will have to be further explored.
\end{abstract}

Keywords $\mathrm{Mg}_{2}$ Si-based thermoelectric materials $\cdot$ Mechanical alloying $\cdot 3 \mathrm{D}$ printing $\cdot$ Electrospinning $\cdot$ Spray

A. C. Marques

acl.marques@fct.unl.pt

1 CENIMAT/I3N, Departamento de Ciência dos Materiais, Faculdade de Ciências e Tecnologia, Universidade Nova de Lisboa, 2829-516 Caparica, Portugal

2 Dipartimento di Scienza Applicata e Tecnologia, Politecnico di Torino, Corso Duca degli Abruzzi 24, 10129 Turin, Italy

3 I3N/Departamento de Física e CICECO, Instituto de Materiais de Aveiro, Universidade de Aveiro, 3810-193 Aveiro, Portugal
4 Departamento de Física e CICECO, Instituto de Materiais de Aveiro, Universidade de Aveiro, 3810-193 Aveiro, Portugal

5 C2TN, Instituto Superior Técnico, Universidade de Lisboa, Campus Tecnológico e Nuclear, Estrada Nacional 10, 2695-066 Bobadela, LRS, Portugal

6 IPFN-IST/UL, Instituto de Plasmas e Fusão Nuclear, Instituto Superior Técnico, Universidade de Lisboa, Estrada Nacional 10, 2695-066 Bobadela, Portugal 


\section{Introduction}

The increasing energy demand worldwide has been driving the search for new, clean, renewable and sustainable energy sources. Solar, wind and hydropower energy sources are expected to fulfill future energy needs and replace energy sources based on fossil fuels. However, currently, these still assure about $90 \%$ of the world's electricity generation with low operating efficiency (30-40\%) and large annual waste of heat to the environment (15 TW) [1]. Such large amount of wasted heat can be directly converted into electricity by solid-state generators based on the thermoelectric (TE) materials, using the Seebeck effect. Nowadays, thermoelectric generators (TEG) are already powering a number of devices in a very broad field of applications, ranging from medical, military and space applications, infrared sensors, computer chips, battery charging, waste heat recovery (e.g. from car exhausts) to rural home electrification [2-4]. Although TEGs have many advantages such as of compactness, low complexity, high reliability and silent operation (no moving parts), low maintenance cost and environmental compatibility of operation, they are not massively used due to their low TE conversion efficiency $(<10 \%)$. In fact, TEGs are actually used only in niche markets where the reliability is more important than performance and cost is not a main consideration [5]. Some of the issues with current TEGs hindering their proliferation are the lack of stability at extremes temperatures, along with problems of environmental friendliness, availability, and high costs of the base materials and the synthesis. Therefore, materials such as $\mathrm{Mg}_{2} \mathrm{Si}$ have recently attracted much attention: these alloys have been demonstrated as good TEG candidate base materials as their synthesis has become easier and achievable by a variety of methods, their constituent elements are nontoxic (contrarily to direct competitors such as $\mathrm{PbTe}$ and $\mathrm{CoSb}_{3}$ ), abundant and light weight. The base silicide thermoelectric properties can be enhanced and tuned through doping, increasing the conversion efficiency in many applications (e.g. industrial furnaces, automobile exhausts, and incinerators in the mid-temperature range $230-730^{\circ} \mathrm{C}$ ). For instance, $\mathrm{Mg}_{2} \mathrm{Si}$ doped with $\mathrm{Sb}, \mathrm{Al}$ and $\mathrm{Bi}$ has been used for the low and high temperature ends, respectively [6], while double doping allows higher figures of merit (ZT), currently in the range of 0.8-1.1 [7,8], with new developments promising ZT values higher than 1.6 [9]. However, an important issue affecting $\mathrm{Mg}_{2} \mathrm{Si}$-based TEGs is the lack of shape control of the traditional synthesis methods, mostly relaying on ingots formation. This makes it difficult or even impossible to properly adapt to curved heat sources, inevitably introducing higher thermal/heat transfer impedances, leading to considerable heat losses and lower energy conversion efficiencies of the devices. A new approach is herein devised to overcome the challenge of shape: it consists in the production of $\mathrm{Mg}_{2} \mathrm{Si}$ powders through a simple and cost-effective process (relying on the combination of ball milling with thermal annealing), for subsequent formulation of thermoelectric pastes suitable for 3D printing, electrospinning and spray technologies. The major problems with the $\mathrm{Mg}_{2} \mathrm{Si}$ powder synthesis and paste formulation are related to the high reactivity of $\mathrm{Si}$ and $\mathrm{Mg}$ powders with oxygen, demanding the use of an inert atmosphere, e.g. a glove box filled with Ar, and limits the selection of solvents and polymers to oxygen-free compounds. One should note that the need for developing thermoelectric parts with any form or shape is a very actual topic that has been differently addressed in other research works, for instance, through the development of $\mathrm{Bi}_{2} \mathrm{Te}_{3}$-based inorganic paints with $\mathrm{Sb}_{2} \mathrm{Te}_{3}$ as a sintering aid [10]. The $\mathrm{Mg}_{2} \mathrm{Si}$ pastes herein proposed can be a competitive alternative applicable in a broad range of TEGbased applications, e.g. from the automobile to the textile sectors, here in the form of woven fabrics of functional fibers.

\section{Materials and methods}

Magnesium and silicon powders of less than $44 \mu \mathrm{m}$ nominal grain size (mesh 325) - from Alfa Aesar with 99.8\% and $99.5 \%$ purity, respectively — were loaded in a 2:1 mass ratio into a $50 \mathrm{~mL}$ agate bowl along with hexane and three $20 \mathrm{~mm}$ diameter agate balls to be mechanically alloyed in a high energy planetary ball mill (Retsch PM100). Hexane was added to prevent agglomeration of $\mathrm{Mg}$ powder on the walls and milling balls. The fluid and balls-to-powder mass ratios were $2: 1$ and 10:1, respectively. To reduce and homogenize the powder grain size, milling times of $2 \mathrm{~h}, 5 \mathrm{~h}$ and $10 \mathrm{~h}$ were tested. The powders and hexane fluid were weighted and transferred to the mill bowl inside a glove box filled with Ar gas. As the agate bowl is sealed inside the glove box with an o-ring fitting lid secured by a custom-made clamp, Ar will also be the atmosphere inside the bowl during the mill, avoiding oxidation of the reactants. The rotational speed was $400 \mathrm{rpm}$ with $5 \mathrm{~min}$ pauses every $30 \mathrm{~min}$, in all cases; after milling, the resulting powder was collected in the glove box and directly loaded in an alumina crucible for Ar thermal annealing at a flow rate of $\sim 0.35 \mathrm{~L} / \mathrm{min}$. The holding temperature was set between 350 and $590^{\circ} \mathrm{C}$, depending on the powders grain size. The annealing temperatures for the unmilled $\left(590{ }^{\circ} \mathrm{C}\right)$, and the $2 \mathrm{~h}, 5 \mathrm{~h}\left(410^{\circ} \mathrm{C}\right)$ and $10 \mathrm{~h}$ $\left(350{ }^{\circ} \mathrm{C}\right)$ milled powders were defined from the differential scanning calorimetry (DSC) heat flow curves, simultaneously performed with thermogravimetric measurements (TGA). Both measurements were simultaneously performed 
in the thermal analyser STA 449 F3 Jupiter under different atmospheres (air and $\mathrm{N}_{2}$ ) from room temperature up to $1000{ }^{\circ} \mathrm{C}$, at a rate of $20 \mathrm{~K} / \mathrm{min}$.

For all samples, the annealing temperature profiles consisted of a heating ramp of $\sim 15{ }^{\circ} \mathrm{C} / \mathrm{min}$ to the desired holding temperature, and a holding time of $\sim 75 \mathrm{~min}$, after which the temperature was ramped down to $\sim 160{ }^{\circ} \mathrm{C}$. Then, the furnace was turned off and the powders left to cool to room temperature.

The synthetized $\mathrm{Mg}_{2}$ Si powders were mixed with polystyrene (PS) - from Sigma Aldrich, Mw 350,000—in xylene solutions for obtaining $n$-type thermoelectric paste formulations-one per application method: 3D printing, spraying and electrospinning. For 3D printing, the $\mathrm{Mg}_{2} \mathrm{Si}$ powders were blended with a solution of $20 \%$ wt of polystyrene in xylene in the mass proportions of $43 / 57$ (formulation 1) and 40/60 (formulation 2). These formulations were extruded in a home-adapted 3D printer equipped with a hot plate set to $50{ }^{\circ} \mathrm{C}$ to favor the fast evaporation of xylene. Fibers of $\mathrm{Mg}_{2} \mathrm{Si}$ were produced by low pressure $\mathrm{N}_{2}$-spray gun (Wuto) using a diluted version of formulation 2 and by electrospinning using a blend of $\mathrm{Mg}_{2} \mathrm{Si}$ powders with a $35 \%$ wt of PS solution in a mass proportion 7:93 (formulation 3). This was loaded into a syringe (B. Braun) connected to a blunt metallic needle with an internal diameter of $1.19 \mathrm{~mm}$ (18G from ITEC, Iberiana Technical). A syringe pump (NewEra SyringePump.com) was used to eject the solution at a controllable speed $(0.2 \mathrm{~mL} / \mathrm{h})$ through the needle while a high voltage of $20 \mathrm{kV}$ was applied (Glassman high voltage-power supply). A grounded Al static plate was placed at $15 \mathrm{~cm}$ from the needle to collect the fibers. A fourth paste was formulated with polyvinylidene difluoride (PVDF) solution in dimethylformamide (DMF) and then tested to produce bulk $\mathrm{Mg}_{2} \mathrm{Si}$ parts. The PVDF was heated together with DMF at $70{ }^{\circ} \mathrm{C}$ until PVDF is completely dissolved.

The temperatures at which the PS polymer can be burned out from the printed pieces were determined by DST/TGA to be $\sim 460-470{ }^{\circ} \mathrm{C}$ (depending on the PS concentration). A holding time of $\sim 90$ min preceded by a heating ramp of $2-5{ }^{\circ} \mathrm{C} / \mathrm{min}$ revealed to be enough for that end.

The morphology and composition of the milled powders, before and after annealing, were studied using a FEG-SEM Jeol JSM7001F and a Vega 3 TESCAN scanning electron microscopes (SEM), both equipped with an energy dispersive X-ray spectrometer (EDS). The crystalline phases were identified by X-ray diffraction (XRD) using a Panalytical $\mathrm{X}$-PERT Powder diffraction unit, through $\mathrm{Cu} \mathrm{K}_{\alpha}$ radiation $(\lambda=0.1540598 \mathrm{~nm})$. Confocal Raman spectrophotometer (Witec Alpha 300 RAS) using a laser with a wavelength of $532 \mathrm{~nm}$ and $4.11 \mathrm{~mW}$ of power was used to confirm the existence of the $\mathrm{Mg}_{2} \mathrm{Si}$ phase on the synthetized powders and also on both the printed pieces and fibers. The surface area, the pore volume and the average pore size were measured using
Gemini V-2380 surface area analyser from Micromeritics and Gemini v2.0 software. The specific surface area (BrunauerEmmett-Teller, BET, method) was determined from nitrogen adsorption isotherms determination for samples immersed in a liquid nitrogen bath. Barrett-Joyner-Halenda (BJH) method was used to calculate the pore size distribution in the samples. Prior to these measurements, the water vapor and adsorbed gas were removed by purging the samples in nitrogen flow for about $10 \mathrm{~h}$. Over this period, the heat treatment of samples $\mathrm{A}$ and $\mathrm{B}$ was held at $120^{\circ} \mathrm{C}$, while for samples $\mathrm{C}$ at $300^{\circ} \mathrm{C}$.

The thermal conductivity was measured at room temperature (300 K) using the Gustafsson Probe method (Hot Disk) with the Thermal Constant Analyser TPS 2500 S. This method is based on the Transient Plane Source (TPS) technique and uses an electrically conductive double spiral flat sensor that is protected by a kapton $70 \mu \mathrm{m}$ thick film, acting both as pulsed heat source and temperature sensor. The TPS was assembled between two similar 3D printed $10 \mathrm{~mm}$ diameter disks. The measured thermal conductivity is a result of 14 consecutive and equal measurements. All measurement parameters were double checked and the results were consistent, since the residuals of temperature data fitting as a function of time present a random scatter dispersion within a few $1.5 \mathrm{mK}$. This is also indicative of a good contact between the sensor and the twin samples, a stable temperature in the samples and that the heat pulse did not reach the sample boundary.

Electric and thermoelectric characterizations were performed with a home-made setup illustrated in Fig. 1. A temperature difference $(\Delta \mathrm{T})$ is imposed across the piece thickness using a heat source of variable temperature (from 130 to $230{ }^{\circ} \mathrm{C}$ in steps of $25^{\circ} \mathrm{C}$ ) and one TEC1-12707 Peltier module connected to an independent power sourcemeant to work as the cold source. The Seebeck coefficient was determined by imposing a $\Delta \mathrm{T}$ and monitoring it with a FLIRA310 thermal camera, while the thermoelectric voltage $(\Delta \mathrm{V})$ was measured using an Agilent 34420A nanovoltmeter, using $\mathrm{C}$-paste electrodes with conductive tapes on top and connecting to the cold/hot sources. The electrode area was $\sim 70 \mathrm{~mm}^{2}$ and was separated by $\sim 9 \mathrm{~mm}^{2}$. Seebeck coefficient was obtained from the slope of the plot $\Delta V$ versus $\Delta T$ as shown in Fig. 1, subsequently enabling the calculus of the power factor. A variable load resistance connected to the TE elements and $\Delta V$ measurements across terminals, from short-circuit to open-circuit conditions enable power output determination $\left(P_{\text {out }}=I_{\text {out }} \times V_{\text {out }}\right)$.

\section{Results and discussion}

\section{$\mathrm{Mg}_{2} \mathrm{Si}$ powder synthesis}

The SEM images shown in Fig. 2 illustrate the influence of ball milling in the particle size of $\mathrm{Mg}$ - and Si-powders. The

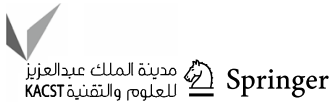




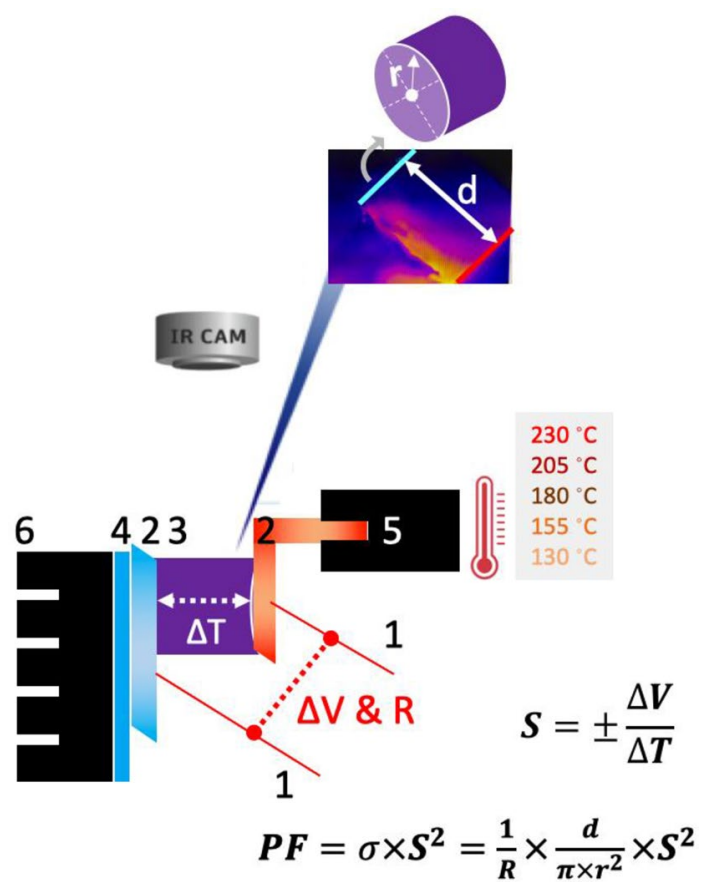

Fig. 1 A schematic of the cross-sectional view of the home-made apparatus for the Seebeck measurements of bulk thermoelectrics. 1, Nano-voltmeter probes to measure the thermo-voltage; 2, conductive tapes attached to the C-paste-based electrodes on the cylinder faces; $3, \mathrm{Mg}_{2} \mathrm{Si}$ thermoelectric cylinder; 4, cold peltier; 5, variable hot source; 6 , heat sink purchased powders shown in figure (a) and (b) consist of irregularly shaped grains with a somewhat heterogeneous size distributions, with mean values and standard deviations of, respectively, $\sim 13.5 \mu \mathrm{m}$ and $7.5 \mu \mathrm{m}$ for $\mathrm{Si}$, and $\sim 37.9 \mu \mathrm{m}$ and $11.9 \mu \mathrm{m}$ for $\mathrm{Mg}$, in compliance with the stated 325 mesh specifications-implying a particle size distribution with upper limit of $\sim 44 \mu \mathrm{m}$. After milling the $\mathrm{Mg}$ - and $\mathrm{Si}$ powders in a 2:1 mass ratio for $2 \mathrm{~h}$ (Fig. $2 \mathrm{c}$ ), $5 \mathrm{~h}$ (Fig. 2d) and $10 \mathrm{~h}$ (Fig. 2e), both shape and grain size distribution become more homogeneous, while the grain size was progressively reduced to $\sim 26.3 \pm 24.9 \mu \mathrm{m}, \sim 8.8 \pm 5.3 \mu \mathrm{m}$ and $\sim 7 \pm .7 \mu \mathrm{m}$, respectively. The milling of the $\mathrm{Mg}$ - and Si- powder mixture was performed not only for reducing and homogenizing the grain size, aiming at enhancing the extrusion of pastes by 3D printing, spray and electrospinning, but also for verifying if any amount of the $\mathrm{Mg}_{2} \mathrm{Si}$ phase had formed as a result of the relatively short duration of the ball milling. Usually, much longer durations are required [11, 12]. XRD measurements on pristine Mg and Si powders, and mixtures of both, followed by $2 \mathrm{~h}, 5 \mathrm{~h}$ and $10 \mathrm{~h}$ milling are shown in Fig. 2. In all diffratograms, only the diffraction lines arising from $\mathrm{Mg}$ and $\mathrm{Si}$ are seen, no significant additional phases were detected ( $\mathrm{MgO}$ fraction was below to $3 \%$ ). Regardless the milling time, the XRD diffratograms from the milled powders can be described as a linear combination of XRD diffratograms of the pure $\mathrm{Mg}$ and $\mathrm{Si}$ commercial powders, with no trace of $\mathrm{Mg}_{2} \mathrm{Si}$ whatsoever. This observation, together with that presented in Fig. 2, clearly demonstrates that milling up to $10 \mathrm{~h}$, does not lead to alloying; it merely decreases the grain sizes and homogenizes
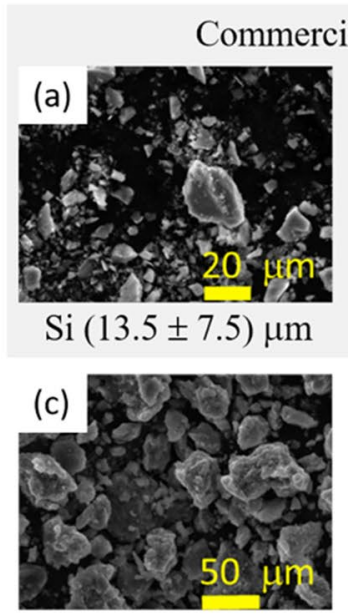

$(26.3 \pm 24.9) \mu \mathrm{m}$

$2 \mathrm{~h}$ milling
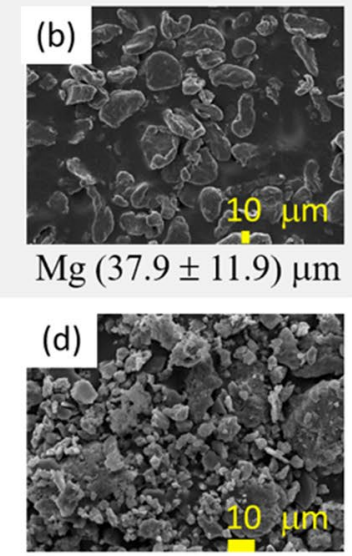

$(8.8 \pm 5.3) \mu \mathrm{m}$

$5 \mathrm{~h}$ milling

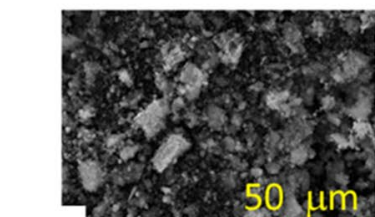

(e)

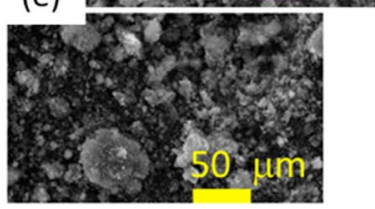

(7.0 \pm 6.7$) \mu \mathrm{m}$

$10 \mathrm{~h}$ milling

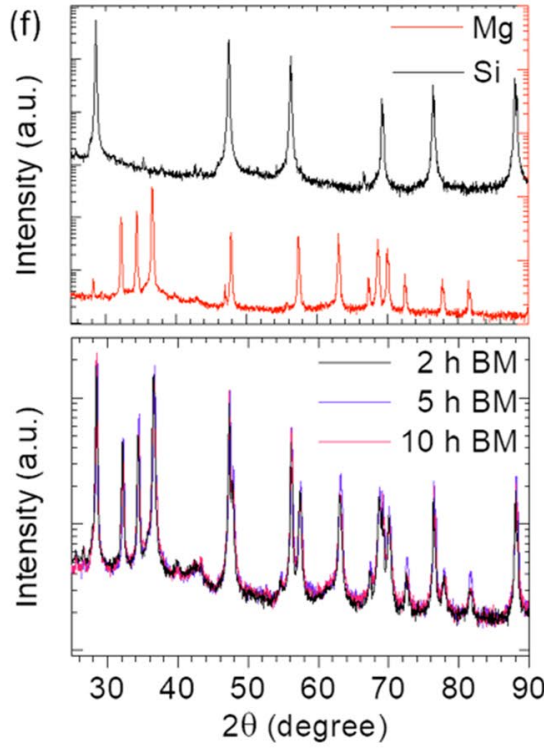

Fig. 2 SEM micrographs of $\mathrm{Si}$ and $\mathrm{Mg}$ commercial powders before $(\mathbf{a}-\mathbf{b})$ and after milling for $2 \mathrm{~h} \mathrm{(c),} 5 \mathrm{~h}(\mathbf{d})$ and $10 \mathrm{~h}(\mathbf{e})$. The average grain size is indicated together with the standard deviation. The XRD diffratograms of the starting $\mathrm{Si}$ and $\mathrm{Mg}$ powders (top) and the milled powders (bottom) are shown in (f) 
$(5.8 \pm 6.2) \mu \mathrm{m}$
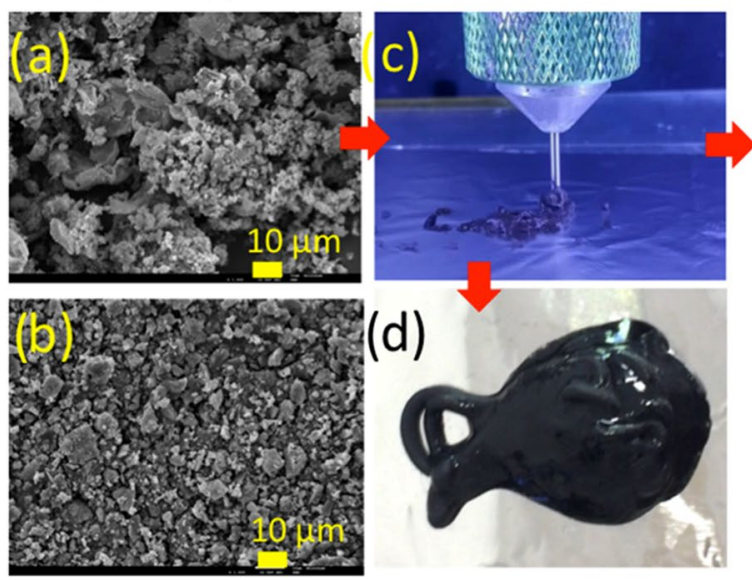

(4.7 \pm 2.2$) \mu \mathrm{m}$

Fig. 3 In the left half: SEM micrographs of $\mathrm{Mg}_{2} \mathrm{Si}$ powders obtained directly by thermal annealing only (a) and after the sequence thermal annealing and $5 \mathrm{~h}$ milling (b); photos of extruded $\mathrm{Mg}_{2} \mathrm{Si}$ paste made with powders formed through thermal annealing only (c) and close-up (d), respectively. In the right half: XRD diffratograms of the

Table 1 XRD phases quantification of powders processed under different conditions

\begin{tabular}{llrlll}
\hline Powder synthesis sequence: & \multicolumn{2}{l}{ Qty. (\%) } & & & \\
\cline { 2 - 6 } & $\mathrm{Mg}_{2} \mathrm{Si}$ & $\mathrm{MgO}$ & $\mathrm{Si}$ & $\mathrm{Mg}$ & $\mathrm{SiO}_{2}$ \\
\hline $\mathrm{Ar} \mathrm{TA}$ & 76.3 & 8.3 & 1.4 & 14.1 & - \\
$5 \mathrm{~h} \mathrm{BM}+\mathrm{Ar} \mathrm{TA}$ & 71.3 & 11.1 & 7.0 & - & 10.6 \\
$\mathrm{Ar} \mathrm{TA}+5 \mathrm{~h} \mathrm{BM}$ & 78.3 & 6.8 & 4.8 & 10.1 & - \\
\hline
\end{tabular}

the size distributions. On the contrary, Fig. 3 XRD diffratograms clearly show that thermal annealing is of paramount importance for the formation of the $\mathrm{Mg}_{2} \mathrm{Si}$ phase. This can be easily obtained through thermal annealing (TA) only of the $\mathrm{Mg}$ - and $\mathrm{Si}$ - powders in a 2:1 mass ratio, even without ball milling (BM). The drawback is that $\mathrm{Mg}_{2}$ Si powders produced in this way lead to a small amount of unreacted $\mathrm{Mg}$ and to grains agglomerations which, as illustrated in Fig. 3, made it impossible to 3D print the pastes formulation with such powders on the available printer, currently operating with needles of inner diameter of $0.61 \mathrm{~mm}$ and $1.19 \mathrm{~mm}$. For mitigating this issue, the $\mathrm{Mg}_{2} \mathrm{Si}$ powders produced by directly annealing the $\mathrm{Si}-\mathrm{Mg}$ powder mix were subsequently milled for $5 \mathrm{~h}$ to reduce and homogenize the particles, making them suitable for manufacturing 3D printing pastes. The XRD diffratogram of $\mathrm{Mg}_{2} \mathrm{Si}$ powders produced in the reverse sequence (i.e. $5 \mathrm{~h} \mathrm{BM} \rightarrow \mathrm{Ar}$ TA) is also included in Fig. 3 for comparison. This does not exhibit the peaks corresponding to a fraction of unreacted $\mathrm{Mg}$ and moreover, quantification through the Rietveld refinement method yields an $\mathrm{Mg}_{2} \mathrm{Si}$

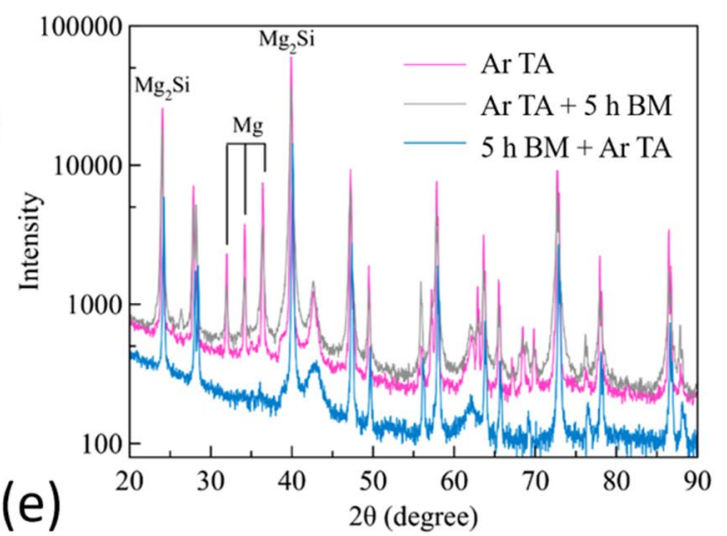

$\mathrm{Mg}_{2} \mathrm{Si}$ powders (e) obtained directly by thermal annealing (pink line) and by thermal annealing and subsequent $5 \mathrm{~h}$ milling (gray line). For comparison, the XRD measurements obtained from powders milled for $5 \mathrm{~h}$ and annealed is also included (blue line)

fraction of $71.3 \%$ for this sequence. As shown in Table 1, similar fractions of $\mathrm{Mg}_{2} \mathrm{Si}$ were also formed through thermal annealing only $(\sim 76.3 \%)$ or in the sequence $\operatorname{Ar} \mathrm{TA} \rightarrow 5 \mathrm{~h}$ $\mathrm{BM}(\sim 78.3 \%)$. Additional phases are due to unreacted $\mathrm{Mg}$ fast oxidization, leading to the $\mathrm{MgO}$ phase as well as unreacted $\mathrm{Si}$, that can also react with $\mathrm{O}_{2}$ and lead to $\mathrm{SiO}_{2}$. The presence of some $\mathrm{MgO}$ along with the $\mathrm{Mg}_{2} \mathrm{Si}$ is not entirely surprising, since the insertion of the powder carrying crucibles in the quartz tubes used for annealing was always done in open air.

The sequence $\mathrm{BM} \rightarrow \mathrm{Ar}$ TA was also performed for a shorter milling duration of $2 \mathrm{~h}$ as shown in Fig. $4 \mathrm{a}$, the XRD diffratograms are compared with that of $\mathrm{Mg}-\mathrm{Si}$ powders processed in the sequence $5 \mathrm{~h} \mathrm{BM} \rightarrow \mathrm{Ar}$ TA. Both diffratograms are very similar which suggests that milling duration only impacts, as expected, in the final grain sizes. However, thermal annealing further reduced down the grain sizes of $\mathrm{Mg}-\mathrm{Si}$ powders produced through $2 \mathrm{~h} \mathrm{BM} \rightarrow \mathrm{Ar} \mathrm{TA}$ to $3 \mu \mathrm{m}$, and $5 \mathrm{~h} \mathrm{BM} \rightarrow \mathrm{Ar}$ TA to $2 \mu \mathrm{m}$, respectively. This is shown in the SEM micrographs of Fig. 4b, $\mathrm{c}$ and may be attributed to the release of high residual stresses which may have led to polygonization and hence to the formation of new small grains with more homogeneous microstructure.

\section{$\mathrm{Mg}_{2}$ Si paste synthesis and application}

The high reactivity of $\mathrm{Si}$ and $\mathrm{Mg}$ powders with oxygen demands the use of solvents and polymers free of oxygen. Polystyrene $\left(\left(\mathrm{C}_{8} \mathrm{H}_{8}\right) n\right)$ and polyvinylidene difluoride $\left.\left(\left(\mathrm{C}_{2} \mathrm{H}_{2} \mathrm{~F}_{2}\right) n-\right)\right)$ polymers proved to be viable polymers when

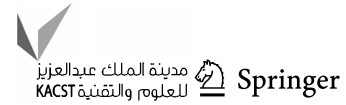




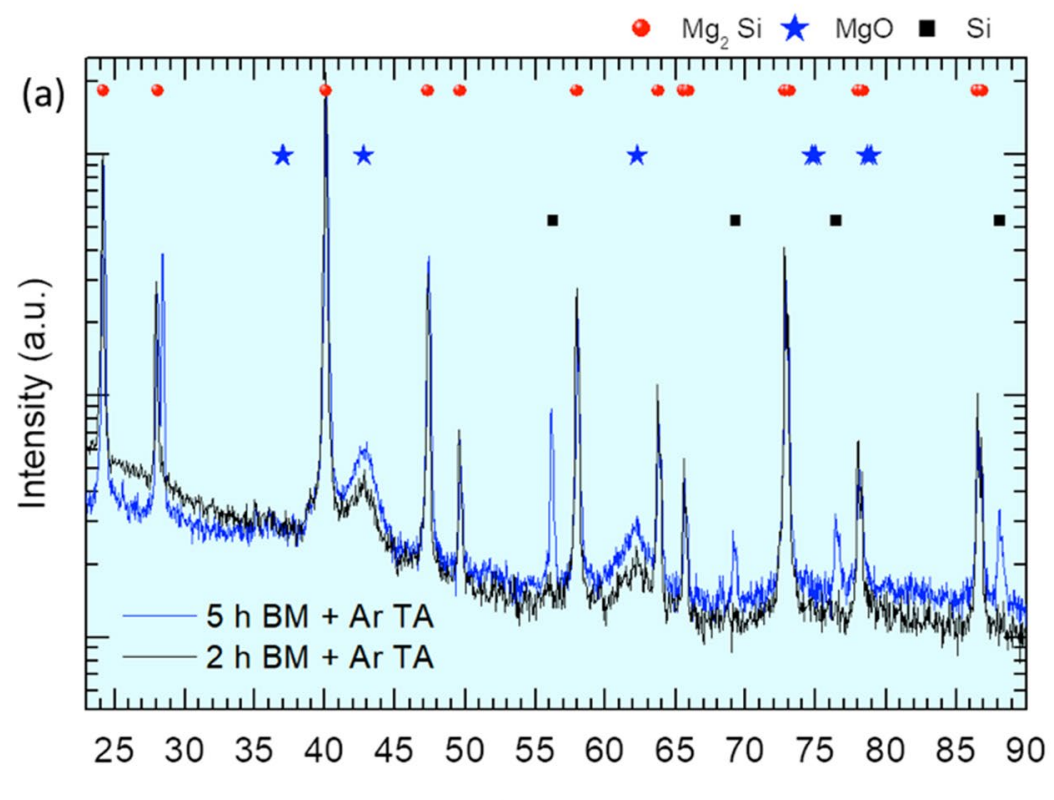

$2 \theta$ (degree)

(b)
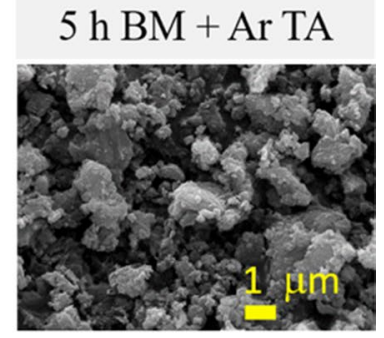

$(2.2 \pm 0.7) \mu \mathrm{m}$

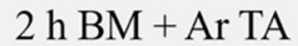

(c)

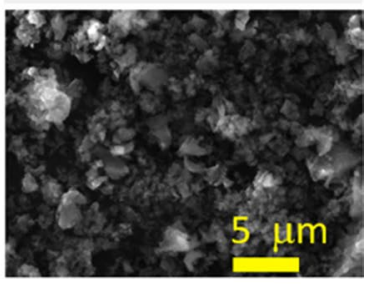

$(3.0 \pm 1.5) \mu \mathrm{m}$
Fig. 4 XRD diffratograms (a) of $\mathrm{Si}-\mathrm{Mg}$ powders ball milled (BM) for $2 \mathrm{~h}$ (black line) and $5 \mathrm{~h}$ (blue line) and next thermally annealed in Ar. The SEM micrographs after the synthesis sequences are also

mixed in the correct proportion with Xylene $\left(\mathrm{C}_{8} \mathrm{H}_{10}\right)$ and Dimethylformamide $\left(\mathrm{C}_{3} \mathrm{H}_{7} \mathrm{NO}\right)$, respectively. Although the latter has in its constitution oxygen, $\mathrm{Mg}_{2} \mathrm{Si}$ is not sensitive to $\mathrm{O}_{2}$ (only to moisture) and it is one of the most recommended solvents for effectively dissolving PVDF. Hence, using this polymer-solvent combination only requires assuring that the fraction of unreacted $\mathrm{Mg}$ and $\mathrm{Si}$ in the synthetized $\mathrm{Mg}_{2} \mathrm{Si}$ powder batch is inexistent or negligible. Also, PVDF should not be discarded because of its difficulty in finding compatible solvents without oxygen, since it has attractive properties for the $\mathrm{Mg}_{2} \mathrm{Si}$ pastes formulation. It is non-toxic, has good thermal stability up to $100{ }^{\circ} \mathrm{C}$, melts at $170^{\circ} \mathrm{C}$, is resistant to chemicals, may exist in different crystalline forms depending on the preparation conditions, and most importantly, it has low water absorption characteristics [13]. Therefore, both polymeric solutions were mixed with the synthetized $\mathrm{Mg}_{2} \mathrm{Si}$ powders for obtaining $n$-type thermoelectric $\mathrm{Mg}_{2} \mathrm{Si}$ paste formulations. Prior to the PVDF paste formulation, three polystyrene paste formulations were derived and extruded by 3D printing, spray and electrospinning. Each paste formulation is described in Table 2, and the ability of producing 3D printed pieces, with a variety of shapes and high finishing quality, and fibers is illustrated in Fig. 5.

For 3D printing, the paste was made of $\mathrm{Mg}_{2} \mathrm{Si}$ powders obtained from different milling times $(5 \mathrm{~h}$ and $2 \mathrm{~h}$ ). Figure $6 \mathrm{a}$ shows that the pieces produced with $5 \mathrm{~h}$ milled powder of lower grain size (formulation 1) are less smooth and have a worst finishing than those produced with higher grain size shown in $\mathbf{b}$ and $\mathbf{c}$. The average grain size taken from each micrograph is indicated together with the standard deviation

Table $2 \mathrm{Mg}_{2} \mathrm{Si}$ paste formulations prepared with polystyrene (PS) solution for $3 \mathrm{D}$ printing and fiber production by spray and electrospinning

\begin{tabular}{llll}
\hline Paste ID & Paste application & $\begin{array}{l}\text { PS solution: } \mathrm{Mg}_{2} \mathrm{Si} \\
\text { powder mass ratio }\end{array}$ & $\begin{array}{l}\text { PS\% wt. } \\
\text { in xylene }\end{array}$ \\
\hline 1 & 3D printing & $57: 43$ & 20 \\
2 & 3D printing and & $60: 40$ & 20 \\
3 & $\begin{array}{l}\text { spray (diluted) } \\
\text { Electrospinning }\end{array}$ & $93: 7$ & 20 \\
\hline
\end{tabular}

powder and with $3 \%$ less amount of $\mathrm{Mg}_{2} \mathrm{Si}$ powder (formulation 2). This latter formulation was next diluted for producing $\mathrm{Mg}_{2} \mathrm{Si}$ fibers by low $\mathrm{N}_{2}$ pressure spray with the Wuto gun and by electrospinning (formulation 3 ). The SEM images of the sprayed fibers are shown in Fig. 6b, c and evidence that these are aligned and incorporate $\mathrm{Mg}_{2} \mathrm{Si}$ grains. Similarly, the SEM images of electrospun fibers shown in Fig. $6 c$, d reveal their elongated beaded-like morphology, that includes $\mathrm{Mg}_{2} \mathrm{Si}$ aggregates. The Raman spectra measured on the printed pieces and sprayed fibers obtained with paste formulations 2 and 3, respectively, are also included in Fig. 6. The Raman peaks at $\sim 251 \mathrm{~cm}^{-1}$ are assigned to $\mathrm{Mg}_{2} \mathrm{Si}$ phonon peaks identified in the literature as arising at 256-260 $\mathrm{cm}^{-1}$, being the shift probably due residual strain $[14,15]$.

The porosity of three printed small cylindrical pieces (made with formulation 2) was also determined by means 
3D printing

(a)
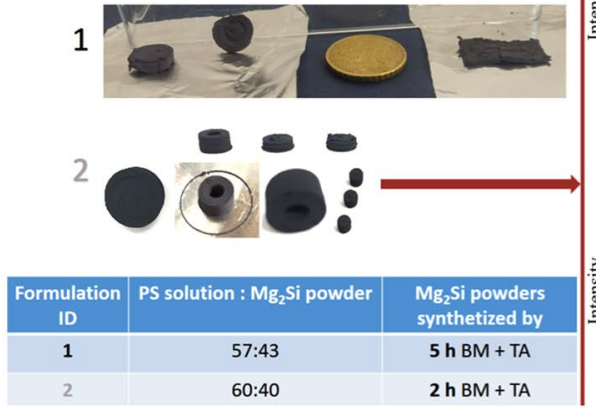

Spray fibers

(b)

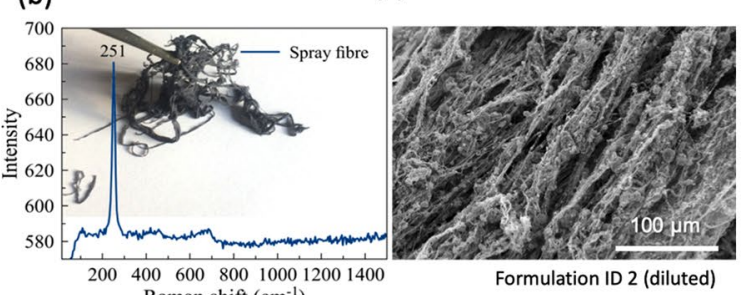

Raman shift $\left(\mathrm{cm}^{-1}\right)$

Electrospun fibers

(d)

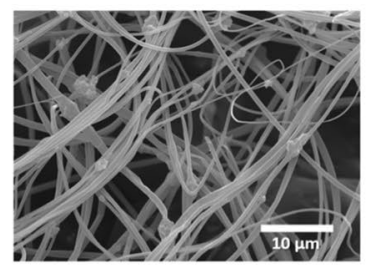

(e)

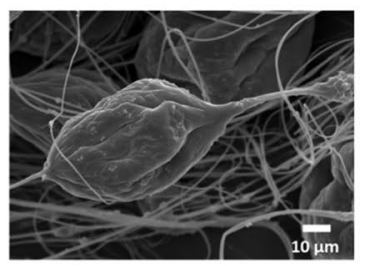

Formulation ID 3

Fig. 5 a Pieces printed with $\mathrm{Mg}_{2} \mathrm{Si}$ pastes following formulations 1 and 2 and $\mathrm{SEM}$ images of sprayed (b, c) and electrospun PS/Mg $2 \mathrm{Si}$ fibers (d, e) produced with paste formulations 2 and 3, respectively. 3D-printing formulations are specified in Table 2

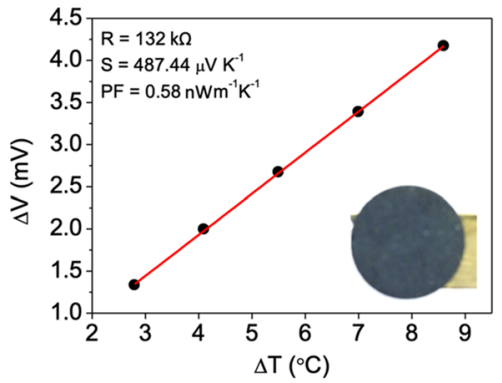

Fig. 6 Thermo-voltage vs. temperature difference plot measured from an $\mathrm{Mg}_{2} \mathrm{Si}$ pellet. From the linear fit slope, the Seebeck coefficient was determined and enabled the calculus of the power factor, being both values indicated

of BET measurements, preceded by a standard $10 \mathrm{~h}$ thermal treatment. Two pieces, $\mathrm{A}$ and $\mathrm{B}$, were heated at $120^{\circ} \mathrm{C}$ and one at $300{ }^{\circ} \mathrm{C}$, piece $\mathrm{C}$. BET measurements on pieces $\mathrm{A}$ and $B$ yielded a mean specific surface area of $4.11 \pm 0.67 \mathrm{~m}^{2} / \mathrm{g}$, a total pore specific volume of $0.0030 \pm 0.0002 \mathrm{~cm}^{3} / \mathrm{g}$, and a pore size of $6.00 \pm 0.34 \mathrm{~nm}$, while for piece $\mathrm{C}$, these values proved to be significantly smaller: $14.9 \pm 2.4 \mathrm{~m}^{2} / \mathrm{g}, 0.0194 \pm$ $0.0013 \mathrm{~cm}^{3} / \mathrm{g}$ and $7.20 \pm 0.41 \mathrm{~nm}$, respectively. The reason is mainly attributed to the polymer evaporation that according to the literature is foreseen to occur at $210-249^{\circ} \mathrm{C}$, and at $\sim 470{ }^{\circ} \mathrm{C}$ as determined by DSC/TGA measurements. Temperature at which polymer removal is expected to be completed. Such porosity after the polymer removal, led as expected, to a low thermal conductivity $0.226 \pm 0.001 \mathrm{~W} /$ $\mathrm{mK}$, that is significantly lower than the experimental (range from 7.8 to $4.0 \mathrm{~W} / \mathrm{mK}$ at $323 \mathrm{~K}$ and $623 \mathrm{~K}$, respectively, [16]) and theoretical ( 9.5 to $10.5 \mathrm{~W} / \mathrm{mK}$ at $300 \mathrm{~K}$ [17]) values reported to $\mathrm{Mg}_{2} \mathrm{Si}$, but led to insulating and mechanically fragile pieces. For that reason, a new paste formulation was devised. This was constituted by a solution of PVDF in DMF high boiling point solvent $\left(153{ }^{\circ} \mathrm{C}\right)$. The aim was to prevent larger pores formation due to rapid solvent evaporation before and during the annealing for the polymer removal. Besides, the amount of polymeric solution in the paste was reduced. The mass ratio of PVDF solution to $\mathrm{Mg}_{2} \mathrm{Si}$ powder was optimized to $8 / 92$ (formulation 4), which immediately led to the production of bulk $\mathrm{Mg}_{2} \mathrm{Si}$ thermoelectric pieces with electrical resistance and impressive thermoelectric properties. The polymeric solution is constituted by $6.6 \%$ wt of PVDF in DMF.

\section{Thermoelectric characterization}

The thermoelectric characterization of $\mathrm{Mg}_{2} \mathrm{Si}$ powder and bulk pieces produced with the 'PVDF in DMF' formulation is next presented.

\section{$\mathrm{Mg}_{2}$ Si pellet}

Approximately, $283 \mathrm{mg}$ of $\mathrm{Mg}_{2} \mathrm{Si}$ powder was 15 ton pressed to form a pellet with a diameter of $\sim 12.84 \mathrm{~mm}$ and 


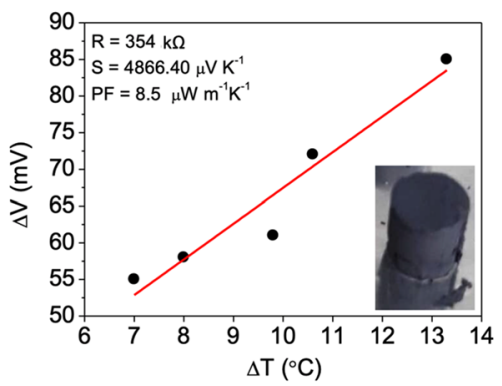

Fig. 7 Thermo-voltage vs. temperature plot measured from a bulk $\mathrm{Mg}_{2} \mathrm{Si}$ piece made with PVDF in DMF solution

a thickness of $\sim 1.55 \mathrm{~mm}$. Measurements of the pellet electrical resistance and voltage under a temperature difference was plotted as shown in Fig. 6 for determining the Seebeck coefficient, where the former one corresponds to $132 \mathrm{k} \Omega$ and the later to $487 \mu \mathrm{V} / \mathrm{K}$. This Seebeck coefficient value is in line with those reported in the literature for sintered $\mathrm{Mg}_{2} \mathrm{Si}$, circa $500 \mu \mathrm{V} / \mathrm{K}$ [18], assuring that the $\mathrm{Mg}_{2} \mathrm{Si}$ powder herein synthetized for formulating the pastes is thermoelectric. The measured Seebeck coefficient value is slightly smaller, because of the formation of other minor phases, that are: unreacted $\mathrm{Si}$ and $\mathrm{Mg}$, and $\mathrm{SiO}_{2}$ and $\mathrm{MgO}$ - as previously concluded, the powder is not pure $\mathrm{Mg}_{2} \mathrm{Si}$. The curve of Fig. 6 not only enabled the calculus of the Seebeck coefficient, but also of the power factor, $\sim 0.58 \mathrm{nW} / \mathrm{mK}$.

\section{$\mathrm{Mg}_{2} \mathrm{Si}$ pieces made with PVDF polymeric solution}

Figure 7 shows the thermo-voltage measured as a function of the temperature difference applied to a bulk cylindrical piece made of paste constituted by $92 \%$ of $\mathrm{Mg}_{2} \mathrm{Si}$ and $8 \%$ of solution of PVDF in DMF prior sintering. This curve enabled the calculus of the Seebeck $(\sim 4866.40 \mu \mathrm{V} / \mathrm{K})$ coefficient and of the power factor $(\sim 8.5 \mu \mathrm{W} / \mathrm{mK})$ as illustrated in Fig. 7 . The first is in the range of competitor materials such as BiTe and $\mathrm{CoSb}_{3}(\sim 290-700 \mathrm{~V} / \mathrm{K})$ but contrary to $\mathrm{CoSb}_{3}(5 \mu \mathrm{W} /$ $\mathrm{mK})$, BiTe still presents a higher power factor $(\sim 0.25 \mathrm{~mW} /$ $\mathrm{mK}$ ) than that of the $\mathrm{Mg}_{2} \mathrm{Si}$ bulk piece prior to the polymer removal. This is evidently contributing to the thermoelectric properties measured from such $\mathrm{Mg}_{2} \mathrm{Si}$ bulk piece. A few days later, the polymer inside the piece must have degraded, because it was no longer possible to measure the electrical resistance from this sample. Porosity initially filled by the polymer must have been partially undone due to the polymer degradation, which prevented the electrical resistance measurement. According to the literature, during useful life, polymers may be influenced by heat, oxygen, sunlight, mechanical stress, etc. Also solvents can be photo-oxidized, hydrolyzed or thermally decompose, and as a result degrade the polymer. Therefore, it is difficult to exactly determine what may have caused the PVDF polymer degradation and hence the lack of thermoelectric property stability before sintering. This piece and other new replicas were sintered through a pressureless sintering method that consisted in a long thermal annealing performed at $400{ }^{\circ} \mathrm{C}$ under inert atmosphere. However, this sintering method, which cannot be combined with mechanical pressure, proved to be ineffective, without leading to the consolidation of the bulk $\mathrm{Mg}_{2} \mathrm{Si}$ pieces produced with a mean grain size of $2-3 \mu \mathrm{m}$, even after two steps of $16 \mathrm{~h}$. The porosity and strength properties were not sufficiently enhanced since after each sintering attempt, it was not possible to measure the electrical resistance. The sample composition was not significantly altered for all sintering attempts performed at $400{ }^{\circ} \mathrm{C}$ up to $32 \mathrm{~h}$. The Raman spectra in Fig. 8 show that the dominant phase remains that of $\mathrm{Mg}_{2} \mathrm{Si}\left(247 \mathrm{~cm}^{-1}\right.$ peak) which coexists with very small amounts of $\mathrm{MgO}\left(1348\right.$ and $1577 \mathrm{~cm}^{-1}$ peaks). Above $400{ }^{\circ} \mathrm{C}, \mathrm{Mg}_{2} \mathrm{Si}$ is not thermally stable and other compounds start to form $\sim \mathrm{MgO}$ at $465{ }^{\circ} \mathrm{C}, \sim \mathrm{SiO}_{2}$ at $710{ }^{\circ} \mathrm{C}$ and $\sim \mathrm{Mg}_{2} \mathrm{SiO}_{4}$ at $\sim 1000{ }^{\circ} \mathrm{C}$.

An alternative pressureless method that predictably may be used is the hot isostatic pressing sintering method, compatible with 3D shapes. This subjects a sample to both elevated temperature and isostatic gas pressure in a heated high pressure vessel filled with an inert gas for avoiding chemical reactions. This synthesis method may be an alternative that together with others may be worth to explore to overcome

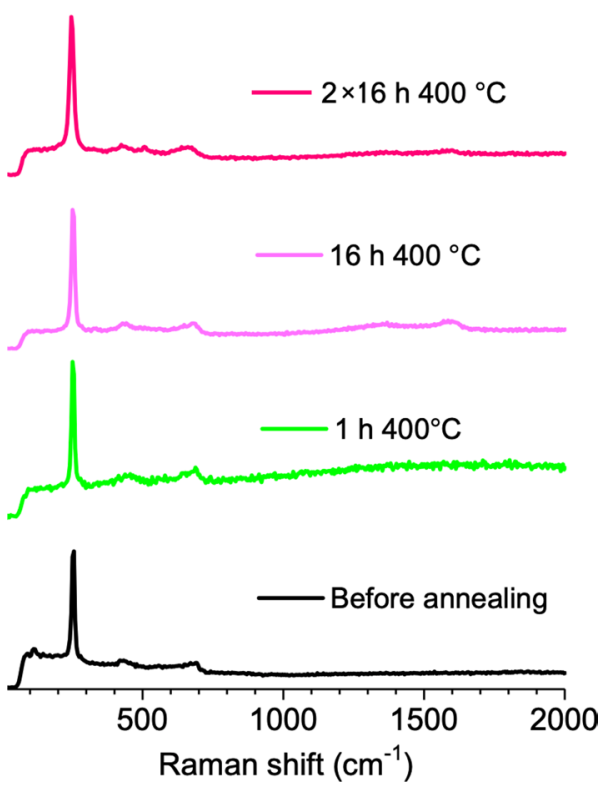

Fig. 8 Raman spectra measured from replicas $\mathrm{Mg}_{2} \mathrm{Si}$ pieces made of $92 \%$ of $\mathrm{Mg}_{2} \mathrm{Si}$ and $8 \%$ of solution of PVDF in DMF before and after sintering performed at $400{ }^{\circ} \mathrm{C}$ of different durations: $1 \mathrm{~h}, 16 \mathrm{~h}$ and $32 \mathrm{~h}$. Black and green curves correspond to one sample before and after sintering and pink curves correspond to another sample, first sintered by $16 \mathrm{~h}$ and next to another $16 \mathrm{~h}$ sintering (the $32 \mathrm{~h}$ were not followed) 
this sintering challenge and become the silicide's extrusion viable in the production of bulk thermoelectric parts.

\section{Conclusions}

Magnesium silicide powders, $\mathrm{Mg}_{2} \mathrm{Si}$, for TE applications were successfully synthesized by combining ball milling and thermal annealing. Ball milling alone does not yield $\mathrm{Mg}_{2} \mathrm{Si}$, as evidenced by XRD analysis, but it is needed to homogenize the particle size distribution and bring its overall dimensions to values suitable for their use in pastes compatible with techniques such as 3D printing, spray and electrospinning.

Although we have proven that $\mathrm{Mg}_{2} \mathrm{Si}$ may also be synthetized directly by thermal annealing only (without milling), this option requires higher processing temperature and revealed to be not compatible with some $3 \mathrm{D}$ printers operating with needles of inner diameter $\leq 1.19 \mathrm{~mm}$.

The formulation of $\mathrm{Mg}_{2} \mathrm{Si}$ pastes with polystyrene and xylene proved to be viable for producing thermoelectric parts with varied shapes and fibers by means of 3D printing, low-pressure spray and electrospinning. Despite feasible, the PS-based paste 3D printing gives rise to very porous pieces, which hindered electrical and thermoelectrically characterization. As a result, the $\mathrm{Mg}_{2} \mathrm{Si}$ content in a new paste formulation was significantly increased and the polymeric solution changed to PVDF in DMF solution. This proved to be a viable formulation to generate bulk $\mathrm{Mg}_{2} \mathrm{Si}$ pieces with good thermoelectric properties (i.e. large Seebeck coefficient of $4866 \mu \mathrm{V} / \mathrm{K}$ and power factor of $8.5 \mu \mathrm{W} / \mathrm{mK}$ ). However, the performance suffers from degradation over time, probably due to changes in the polymer properties. Also, the long pressureless sintering, performed at $400{ }^{\circ} \mathrm{C}$ due to the low thermal stability $\mathrm{Mg}_{2} \mathrm{Si}$, has not been successful, which demonstrated that this sintering method does not allow consolidating the 3D pieces through pores reduction. Definitely, other alternatives will have to be explored to enable the silicides's pastes formulation to be used in multiple extrusion techniques such as 3D printing and fiber making, which requires further optimization.

Acknowledgements This work was mainly funded by H2020ICT-2014-1, RIA, TransFlexTeg-645241, and ERC-CoG-2014, CapTherPV, 647596, and partially funded by FEDER funds through the COMPETE 2020 Program and National Funds through FCTPortuguese Foundation for Science and Technology under the project UID/CTM/50025/2013. And co-supported by: (1) FCT-Portugal, through the contracts UID/Multi/04349/2013 and POCI-01-0145FEDER-016674 and (2) CICECO-Aveiro Institute of Materials through the project POCI-01-0145-FEDER-007679 (FCT ref. UID/ CTM/50011/2013), financed by national funds through the FCT/ MEC and when appropriate co-financed by FEDER under the PT2020 Partnership Agreement. The authors would like to thank the use of electrospinning apparatus at the Biomaterials Laboratory from Soft and Bio-functional Materials Group (CENIMAT/I3 N). And A.C. Baptista also acknowledges FCT-MEC for her postdoctoral grant with reference SFRH/BPD/104407/2014.

Open Access This article is distributed under the terms of the Creative Commons Attribution 4.0 International License (http://creativeco mmons.org/licenses/by/4.0/), which permits unrestricted use, distribution, and reproduction in any medium, provided you give appropriate credit to the original author(s) and the source, provide a link to the Creative Commons license, and indicate if changes were made.

\section{References}

1. Roco, M.C., Mirkin, C.A., Hersam, M.C.: Nanotechnology Research Directions for Societal Needs in 2020: Retrospective and Outlook. Springer, Netherlands (2011)

2. Jeffrey Snyder, G., Toberer, E.S.: Complex thermoelectric materials. Nature Mater. (2008). https://doi.org/10.1038/nmat2090

3. Li, P., Cai, L., Zhai, P., Tang, X., Zhang, Q., Niino, M.: Design of a concentration solar thermoelectric generator. J. Electron. Mater. 39, 1522-1530 (2010). https://doi.org/10.1007/s1166 4-010-1279-0

4. Vargas-Almeida, A., Olivares-Robles, M.A., Camacho-Medina, P.: Thermoelectric system in different thermal and electrical configurations: its impact in the figure of merit. Entropy 15, 2162-2180 (2013). https://doi.org/10.3390/e15062162

5. Riffat, S.B., Ma, X.: Thermoelectrics: a review of present and potential applications. Appl. Therm. Eng. 23, 913-935 (2003). https://doi.org/10.1016/S1359-4311(03)00012-7

6. Hayatsu, Y., Iida, T., Sakamoto, T., Kurosaki, S., Nishio, K., Kogo, Y., Takanashi, Y.: Fabrication of large sintered pellets of Sb-doped n-type $\mathrm{Mg}_{2} \mathrm{Si}$ using a plasma activated sintering method. J. Solid State Chem. 193, 161-165 (2012). https://doi. org/10.1016/j.jssc.2012.07.008

7. Joshi, G., Lee, H., Lan, Y., Wang, X., Zhu, G., Wang, D., Gould, R.W., Cuff, D.C., Tang, M.Y., Dresselhaus, M.S., Chen, G., Ren, Z.: Enhanced thermoelectric figure-of-merit in nanostructured p-type silicon germanium bulk alloys. Nano Lett. 8, 4670 (2008). https://doi.org/10.1021/n18026795

8. Poudel, B., Hao, Q., Ma, Y., Lan, Y., Minnich, A., Yu, B., Yan, X., Wang, D., Muto, A., Vashaee, D., Chen, X., Liu, J., Dresselhaus, M.S., Chen, G., Ren, Z.: High-thermoelectric performance of nanostructured bismuth antimony telluride bulk alloys. Science 320, 634 (2008). https://doi.org/10.1126/science.1156446

9. Trivedi, S.B., Kutcher, S.W., Rosemeier, C.A., David, M., Jogender, S.: Magnesium and manganese silicides for efficient and low cost thermo-electric power generation. United States 616, 21152 (2013). https://doi.org/10.2172/1108470

10. Park, S.H., Jo, S., Kwon, B., Kim, F., Ban, H.W., Lee, J.E., Gu, D.H., Lee, S.H., Hwang, Y., Kim, J.-S., Hyun, D.-B., Lee, S., Choi, K.J., Jo, W., Son, J.S.: High-performance shape-engineerable thermoelectric painting. Nature Commun. 7, 13403 (2016). https://doi.org/10.1038/ncomms13403

11. Loannou, M., Hatzikraniotis, E., Lioutas, Ch., Hassapis, Th, Altantzis, Th, Paraskevopoulos, K.M., Kyratsi, Th: Fabrication of nanocrystalline $\mathrm{Mg}_{2} \mathrm{Si}$ via ball milling: structural studies. Powder Technol. 272, 523-532 (2012). https://doi. org/10.1016/j.powtec.2011.11.014

12. Wang, L., Qin, X.Y., Xiong, W., Chen, L., Kong, M.G.: Thermal stability and grain growth behavior of nanocrystalline $\mathrm{Mg}_{2}$ Si. Mater. Sci. Eng. A 434, 166-170 (2006). https://doi. org/10.1016/j.msea.2006.06.130 
13. Thomas, P., Satapathy, S., Dwarakanath, K.D., Varma, K.B.R.: Dielectric properties of $\mathrm{Ply}$ (vinylidene fluoride)/ $/ \mathrm{CaCu}_{3} \mathrm{Ti}_{4} \mathrm{O}_{12}$ nanocrystal composite thick films. Express Polymer Lett. 2010, 4 (2010). https://doi.org/10.3144/expresspolymlett.2010.78

14. Galkin, K.N., Galkin, N.G.: Silicon overgrowth atop low-dimensional $\mathrm{Mg}_{2} \mathrm{Si}$ on $\mathrm{Si}(111)$ : structure, optical and thermoelectrical properties. Phys. Procedia 11, 55-58 (2011). https://doi. org/10.1016/j.phpro.2011.01.013

15. Dotsenko, S.A., Galkin, K.N., Bezbabny, D.A., Goroshko, D.L., Galkin, N.G.: Formation, optical and electrical properties of a new semiconductor phase of calcium silicide on Si(111). Phys. Procedia 23, 41-44 (2012). https://doi.org/10.1016/j.phpro .2012.01.011

16. Wunderlich, W., Suzuki, Y., Gibo, N., Ohkuma, T., Al-Abandi, M., Khan, A.U., Mori, T.: Thermoelectric properties of $\mathrm{Mg}_{2} \mathrm{Si}$ produced by new chemical route and SPS. Inorganics 2, 351-362 (2014). https://doi.org/10.3390/inorganics2020351
17. Boulet, P., Verstraete, M.J., Crocombette, J.-P., Briki, M., Record, M.-C.: Electronic properties of the $\mathrm{Mg}_{2} \mathrm{Si}$ thermoelectric material investigated by linear-response density-functional theory. Comput. Mater. Sci. 50, 847-851 (2011). https://doi.org/10.1016/j.comma tsci.2010.10.020

18. Saleemi, M., Toprak, M.S., Fiameni, S., Boldrini, S., Battiston, S., Famengo, A., Stingaciu, M., Johnsson, M., Muhammed, M.: Spark plasma sintering and thermoelectric evaluation of nanocrystalline magnesium silicide $\left(\mathrm{Mg}_{2} \mathrm{Si}\right)$. J. Mater. Sci. 48, 1940-1946 (2013). https://doi.org/10.1007/s10853-012-6959-0

Publisher's Note Springer Nature remains neutral with regard to jurisdictional claims in published maps and institutional affiliations. 